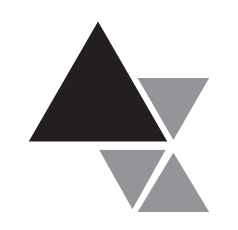

\title{
AS MULHERES AGRICULTORAS NO PROGRAMA DE AQUISIÇÃO DE ALIMENTOS (PAA)
}

\author{
Emma Siliprandi ${ }^{1}$ e Rosângela Cintrão ${ }^{2}$
}

Este artigo apresenta os resultados de uma pesquisa de avaliação sobre a participação das mulheres rurais e suas organizações entre os fornecedores do PAA (Programa de Aquisição de Alimentos), criado pelo governo federal em 2003, como parte do Programa Fome Zero. A pesquisa avaliou a presença das mulheres no programa, em suas diversas modalidades, em todo o território nacional, tomando como base o ano de 2008. Os resultados mostraram que a participação direta das mulheres no PAA é baixa, 23\% em média, variando de 13\% para a modalidade Compra Direta; até 29\% para a Compra Estadual com Doação Simultânea, porém, com muita variação entre Estados e regiões, assim como entre os produtos comercializados. Verificou-se que, embora as mulheres estejam participando diretamente na produção, a comercialização dos produtos da agricultura familiar ainda é feita, na maioria dos casos, com o CPF (Cadastro de Pessoa Física) do homem. Produtoras rurais têm, em geral, dificuldades de participar da comercialização, em função de suas atribuições de gênero; no entanto, tem crescido o número de grupos produtivos de mulheres, para os quais o PAA apresenta-se como uma opção adicional de acesso aos mercados, que pode ter caráter mais permanente e permitir uma melhor estruturação. Verificou-se que o PAA, em suas distintas modalidades, indiscutivelmente valoriza o trabalho feminino, ao criar canais de comercialização para seus produtos, a um preço justo e com formas de operação que atendem às suas necessidades (entregas parceladas, constantes, em pequenas quantidades). No entanto, ainda existem fortes desafios para que possa contribuir de maneira efetiva para a construção de uma maior autonomia econômica das mulheres. O Programa, assim como outras políticas voltadas para a agricultura familiar, em que pese a pressão das próprias mulheres e os esforços em contrário de parte do setor público, tende a reforçar a ideia da unidade familiar de produção como um bloco homogêneo, desconsiderando as diferenças internas existentes, fazendo com que a presença das mulheres agricultoras no mundo público ainda seja uma exceção.

Palavras-chave: agricultura familiar, políticas públicas de segurança alimentar, Programa de Aquisição de Alimentos (PAA), gênero.

\section{WOMEN FARMERS IN THE FOOD AQUISITION PROGRAM}

This paper presents the results of a research about the participation of rural women and their organizations among the sellers to the program called PAA (Food Aquisition Program), established by the Brazilian federal government in 2003, as part of the Zero Hunger Program. The research evaluated womens' presence in the various modalities of the Program, over the whole national territory, in 2008. The results show that women's direct participation is low, 23\% in average, ranging from 13\% for the modality called Direct Buying to $29 \%$ in the modality called State Aquisition with Simultaneous Donation. There was a wide variation among states and regions, as well as among different products. While women participate directly in production, the marketing of products from family farming still uses predominantly men's National Revenue Service identification number (CPF). Rural women producers usually face difficulties to participate in marketing, due to their gender roles. However, there

\footnotetext{
${ }^{1}$ Pesquisadora do Núcleo de Estudos e Pesquisas em Alimentação, da Universidade Estadual de Campinas (NEPA/UNICAMP). Correspondência: NEPA/ UNICAMP, Rua Albert Einstein, 291. Cidade Universitária, CEP 13083-852 Campinas, SP. E-mail: emma@unicamp.br

${ }^{2}$ Pesquisadora autônoma.
} 
is an increasing number of womens' production groups, for which PAA is an additional option to reach markets in a more permanent and structured way. PAA, in its various modalities, undoubtedly values feminine labor, as it establishes marketing channels for their products, with fair prices and procedures that are compatible with their needs (the products are delivered in small, constant amounts). But there are still important challenges to be met before the program can contribute more effectively for womens' wider economic autonomy. Womens' pressures and public agencies' efforts notwithstanding, this program, as well as other policies for family farming, tends to reinforce the idea of the family unit of production as an homogeneous unit, disregarding internal differences. This makes womens' presence in the public world still an exception.

Key-words: family agriculture, public policies of food securtiy, Food Aquisition Program (PAA), gender.

\section{INTRODUÇÃO}

Este artigo trata da participação das mulheres agricultoras no Programa de Aquisição de Alimentos (PAA) do Governo Federal, com base em dados obtidos em uma pesquisa nacional realizada pelas autoras, por solicitação da Companhia Nacional de Abastecimento (CONAB), entre 2009 e 2010, como parte do Programa de Organização Produtiva de Mulheres Rurais (POPMR) ${ }^{3}$. O POPMR tem por objetivo fortalecer as organizações produtivas de trabalhadoras rurais, garantindo o acesso das mulheres às políticas públicas de apoio à produção e à comercialização. Propõe-se a promover a autonomia econômica das mulheres, incentivando a troca de informações, de conhecimentos técnicos, culturais, organizacionais, de gestão e de comercialização, valorizando os princípios da economia feminista e solidária.

A pesquisa fez uma caracterização da presença das mulheres no PAA, em todo o território nacional, tendo em vista contribuir para a ampliação da participação das mulheres rurais nessas e em outras políticas de apoio à agricultura familiar no País ${ }^{[1]}$.

Partiu-se da constatação de que as mulheres produtoras rurais têm dificuldades de se inserir nas atividades de comercialização, em função de as suas atribuições de gênero serem voltadas prioritariamente para a vida doméstica e para o espaço privado. A agricultura familiar se caracteriza por ser uma forma de produção em que a unidade de trabalho se confunde

\footnotetext{
${ }^{3}$ Participam do Programa de Organização Produtiva de Mulheres Rurais, além da Companhia Nacional de Abastecimento (CONAB), o Instituto Nacional de Colonização e Reforma Agrária (INCRA), o Ministério da Agricultura, Pecuária e Abastecimento (MAPA), a Secretaria Especial de Políticas para as Mulheres (SPM) e o Ministério do Trabalho e Emprego (MTE). O Programa é coordenado pelo Ministério do Desenvolvimento Agrário (MDA). Esta pesquisa foi contratada por meio do Projeto PNUD/CONAB-BRA 03/034.
}

com a organização da familia, ambas regidas, em geral, por uma rígida divisão sexual e geracional do trabalho, em que as tarefas e os papéis sociais entre homens e mulheres, adultos, jovens e idosos são distintos e marcados por uma hierarquia. Atividades, espaços de produção e identidades sociais são diferenciados, sendo às mulheres adultas atribuídas as atividades domésticas e de reprodução da família, e aos homens, os espaços ditos "produtivos" e de geração de renda ${ }^{[2-11]}$.

Dentro da unidade familiar, existem diferentes formas de acesso e controle sobre a terra e os demais recursos produtivos (incluindo aqueles decorrentes de políticas públicas) e as mulheres, embora trabalhem em praticamente todas as tarefas da propriedade, muitas vezes não participam da decisão sobre os usos dos recursos ou sobre as prioridades da família e não têm acesso à renda gerada por seu trabalho. Nas estatísticas oficiais, as mulheres agricultoras são maioria entre os "membros não remunerados" da família. Essa forma de organização da unidade produtiva leva a um comprometimento da autonomia pessoal e financeira das mulheres.

Os movimentos de mulheres vêm construindo alternativas, tanto no plano das análises acadêmicas, através da economia feminista, quanto nas ações e lutas por políticas públicas, buscando que estas contribuam para a superação não somente das desigualdades sociais, mas também das desigualdades de gênero. A conquista de uma maior independência financeira para as mulheres rurais, assim como já alcançado em grande parte pelas mulheres urbanas, é uma das questões importantes que vem sendo colocada.

A organização em grupos produtivos é uma das formas buscadas pelas mulheres rurais para fortalecer a sua capacidade produtiva e minimizar os 
problemas enfrentados na comercialização. Muitos grupos começam se propondo a potencializar atividades que normalmente as mulheres faziam em seu cotidiano, tais como artesanato, processamento e/ou comercialização de produtos oriundos dos quintais e arredores da casa, pois são atividades que podem ser realizadas nos intervalos de outras obrigações e não exigem, de imediato, investimentos ou novos conhecimentos. No entanto, à medida que esses grupos vão se consolidando, trazem para as mulheres novos desafios, entre eles os relacionados às atividades de comercialização.

Pesquisas anteriores enfocando as experiências de mulheres agricultoras em grupos produtivos apontam que eles são majoritariamente informais e muitas vezes esporádicos (reunindo-se apenas em períodos de safra ou de entressafra, por exemplo). Contam com pouco financiamento, quase sempre obtidos junto a organizações não-governamentais. Muitas vezes, envolvem o trabalho voluntário das mulheres, na expectativa de obtenção de renda, caso a comercialização dos produtos se efetive, o que nem sempre ocorre. Normalmente esses grupos não se especializam em uma única atividade, dedicandose a diferentes tipos de produtos, conforme o período do ano, combinando a transformação de produtos agrícolas com artesanato, por exemplo. Por serem informais, quase sempre vendem diretamente ao consumidor em mercados locais. $\mathrm{O}$ alcance de outros mercados e a obtenção de maiores ganhos econômicos estão muitas vezes condicionados ao apoio externo de movimentos sociais e de entidades de assessoria (estatais ou de organizações não-governamentais) ${ }^{[12-15]}$.

Essas pesquisas também mostram que a participação das mulheres produtoras rurais em atividades de comercialização, ademais de melhorar a sua renda (mesmo que essa renda seja relativamente pequena), ajuda a promover a sua autonomia econômica. Outro fator muito valorizado pelas participantes é o aumento da sua sociabilidade, porque deixam de ficar presas somente ao espaço doméstico. Há ainda um aumento na sua autoestima, um maior reconhecimento junto às famílias $\mathrm{e}$ às comunidades, o aprendizado de novas tecnologias e a valorização da vivência de novas experiências (tais como viagens, participação em feiras, etc.). No âmbito da família, ocorrem também mudanças, não apenas das rotinas de trabalho, mas também com relação ao seu papel social. Essas mudanças não são necessariamente bem assimiladas no núcleo familiar, em função da perda do monopólio dos homens no gerenciamento da renda obtida, de alterações na divisão sexual do trabalho e de uma maior presença das mulheres na vida pública ${ }^{[16-19]}$.

Levantamentos realizados pela Assessoria Especial em Gênero, Raça e Etnia (AEGRE) do Ministério do Desenvolvimento Agrário (MDA) entre 2005 e 2009 identificaram 920 grupos produtivos de mulheres rurais, em praticamente todos os Estados do País, parte deles já acessando o $\mathrm{PAA}^{4}$. Esses grupos vêm crescendo e se consolidando como oportunidades de geração de renda e trabalho para as mulheres ${ }^{[12,13,20]}$.

A avaliação da participação das mulheres no PAA como uma política que abre possibilidades de comercialização dos produtos da agricultura familiar tem como um dos objetivos centrais identificar em que medida esse programa permite uma inserção igualitária das mulheres rurais e seu acesso à renda obtida, bem como em que medida os grupos produtivos de mulheres rurais estão tendo acesso ao programa.

\section{INFORMAÇÕES GERAIS SOBRE O PROGRAMA DE AQUISIÇÃO DE ALIMENTOS (PAA)}

O PAA foi criado em 2003 como uma das políticas estruturantes da Estratégia Fome Zero ${ }^{5}$. Através dele, podem ser adquiridos alimentos diretamente de agricultores familiares e suas organizações, com dispensa de licitação, para serem doados para instituições sociais (hospitais, entidades assistenciais, escolas) e pessoas em situação de insegurança alimentar e nutricional (que recebem cestas de alimentos), ou serem destinados à formação de estoques públicos. Seus objetivos são, por um lado, incentivar a produção de alimentos na agricultura familiar, permitindo a comercialização para o mercado institucional. Por outro lado, contribuir para o acesso aos alimentos em quantidade, qualidade e regularidade pelas populações em situação de insegurança alimentar e nutricional, e colaborar na formação de estoques. Os recursos do Programa são oriundos do Ministério do Desenvolvimento Social (MDS) e do MDA (estes, a partir de 2006), e ambos contam com pequenas

\footnotetext{
${ }^{4}$ Este levantamento tem lacunas e certamente não abrange a totalidade de grupos produtivos existentes, que são difíceis de serem localizados, justamente por muitos serem pequenos, informais e atuarem em mercados locais.

${ }^{5}$ Foi instituído pelo artigo 19 da Lei no 10.696, de 02 de julho de 2003, e regulamentado pelo Decreto no 4.772, de 02 de julho de 2003.
} 
complementações de Estados e Municípios.

Podem participar do PAA homens e mulheres agricultores familiares, pescadores artesanais, silvicultores, extrativistas, indígenas, membros de comunidades remanescentes de quilombos e agricultores assentados. Para participar do programa é preciso estar enquadrado nos critérios do Programa Nacional de Fortalecimento à Agricultura Familiar (PRONAF), através da apresentação da DAP Declaração de Aptidão ao PRONAF. A DAP foi criada em 2003, pelo MDA, para identificar os agricultores e agricultoras familiares que poderiam ter acesso aos créditos de investimento e custeio no âmbito do PRONAF. É fornecida à família agricultora. O PAA paga pelos produtos fornecidos preços de referência estabelecidos regionalmente, até um determinado limite de valor entregue "por unidade produtiva familiar", o que se traduz num limite "por DAP" 6.

Desde a sua criação, o PAA teve um crescimento contínuo dos valores alocados e do número de fornecedores. Em 2003, iniciou-se com $\mathrm{R} \$ 164$ milhões e 42 mil famílias fornecedoras e em 2008, foram aplicados cerca de $\mathrm{R} \$ 490$ milhões, com compras de 166 mil famílias agricultoras.

Uma revisão sobre estudos realizados em diferentes partes do país sobre a implantação do PAA (a maioria deles voltados para a modalidade Doação Simultânea) ${ }^{[21-39]}$ mostrou que o Programa, nas regiões em que vem sendo executado, vem sendo avaliado positivamente, tanto por gestores e pelo público atendido (produtores e entidades que recebem os alimentos), quanto por acadêmicos, em função dos seguintes fatores:

- contribui para a diversificação da produção de alimentos nas unidades familiares de produção agrícola e para a melhoria da renda e do consumo das famílias de agricultores;

- ajuda na estruturação das unidades de produção familiares e de suas entidades

\footnotetext{
${ }^{6}$ Os limites anuais são definidos por modalidade e têm sido atualizados periodicamente. $\mathrm{O}$ estabelecimento de limites de entrega tem como objetivo, por um lado, permitir que o programa beneficie um maior número de famílias agricultoras, e, por outro, evitar que as famílias se tornem excessivamente dependentes do programa, de forma a estimular que busquem (ou mantenham) outros espaços de comercialização.
}

associativas para participar de outros mercados, pelas melhorias que promove nos processos produtivos, de planejamento e de gestão dos empreendimentos, e de conhecimento de mercados;

- melhora a alimentação de setores vulneráveis e promove o fortalecimento de redes de solidariedade, pela articulação em torno das políticas de segurança alimentar;

- promove o desenvolvimento local, uma vez que, por sua concepção e forma de execução, proporciona o envolvimento de vários segmentos da sociedade e a circulação de recursos dentro do próprio município ou região.

O PAA opera em diferentes modalidades, que sofreram alterações desde o seu início. Atualmente são seis modalidades, três delas operacionalizadas pelo MDS em convênio com Estados e Municípios e três delas pela CONAB. Sob responsabilidade da CONAB estão a Compra da Agricultura Familiar com Doação Simultânea - CPR Doação (conhecida como Doação Simultânea), a Formação de Estoque pela Agricultura Familiar - CPR Estoque (Formação de Estoque ${ }^{7}$ e a Compra Direta da Agricultura Familiar - CDAF (Compra Direta) $)^{8}$. Sob responsabilidade do MDS estão a Compra Direta Local com Doação Simultânea - Estadual e Municipal (PAA CDL Estadual e PAA CDL Municipal) e o PAA - Leite, programa de incentivo à produção e ao consumo de leite?.

\footnotetext{
${ }^{7}$ Apoia a formação de estoques em organizações de agricultores familiares para que possam aguardar o melhor momento de vender os produtos e também para que tenham capital de giro.

${ }^{8}$ Visa a aquisição de produtos para cestas alimentares (para doação), a formação de estoques públicos e a garantia de preços mínimos para os agricultores familiares em caso de grandes safras. A Compra Direta é operada pela $\mathrm{CONAB}$ por meio de polos de compra instalados próximos aos locais de produção. Atua com uma lista fechada de produtos (em torno de 12), armazenáveis e não perecíveis, sendo priorizados aqueles que podem compor as cestas de alimentos doadas a pessoas carentes.
}

9 O PAA Leite é voltado apenas para a região administrativa da Superintendência do Desenvolvimento do Nordeste (SUDENE), abrangendo os Estados da região Nordeste e Norte de Minas Gerais. É operacionalizado por um convênio entre MDS e governos estaduais. O leite é comprado individualmente de agricultores familiares com produção de até 100 litros por dia, é pasteurizado por laticínios credenciados, e doado a famílias previamente cadastradas, com base em critérios de vulnerabilidade estabelecidos pelo programa. 
As modalidades Doação Simultânea, Compra Direta Local Estadual e Compra Direta Local Municipal se assemelham por envolver compras feitas diretamente de agricultores familiares com doação simultânea a pessoas em situação de insegurança alimentar. Todas essas modalidades estabelecem o mesmo limite de entregas anuais por família. A diferença entre as três se dá principalmente na forma de operacionalização. A modalidade Doação Simultânea é operacionalizada pela CONAB através de contratos com organizações de agricultores (associações ou cooperativas, portadoras de Cadastro Nacional de Pessoa Jurídica - CNPJ), que elaboram os projetos e recebem os recursos, responsabilizando-se pela entrega dos produtos, pagamentos dos agricultores e prestação de contas. Já nas modalidades Compra Direta Local são realizados convênios entre o MDS e os governos estaduais ou municipais, que elaboram os projetos e se responsabilizam pelo cadastramento das famílias agricultoras e pela prestação de contas. O pagamento é feito diretamente pelo MDS na conta da pessoa DAP que consta no contrato (marido ou esposa, titulares da DAP) e não é necessária a intermediação de uma organização.

Em 2008, ano utilizado como base nesta pesquisa $^{10}$, a modalidade com maior expressão (em valor e número de fornecedores) foi a Doação Simultânea, que envolveu $43 \%$ do total de famílias agricultoras que acessaram e $37 \%$ do valor total aplicado no conjunto do PAA, com um valor médio vendido por família de $\mathrm{R} \$ 2.882,00$. O PAA Leite é a segunda modalidade em valor ( $36 \%$ dos recursos totais aplicados no PAA) e em número de fornecedores (21\% dos agricultores). O maior peso relativo no percentual de valor total do PAA Leite é explicado por ter um limite anual de vendas por fornecedor que é o dobro daquele das Compras com Doação Simultânea ${ }^{11}$.

${ }^{10} \mathrm{O}$ ano de 2008 foi estabelecido como referência para a pesquisa, por ser, no momento do levantamento quantitativo, o último para o qual se contava com dados consolidados. Na modalidade Compra Direta Local (CDL) Municipal, utilizaram-se os dados de 2007, por inexistência de dados de 2008 em formato digital. Os dados do CDL Estadual apresentaram problemas de compatibilização entre as fontes.

${ }^{11}$ Em 2008 e 2009 o valor máximo de aquisição anual por DAP era de $\mathrm{R} \$ 3.500,00$ para todas as modalidades, exceto o PAA Leite, no qual esse era o valor máximo por semestre. A partir de 2010, o limite para as três modalidades de compra direta com doação simultânea passou para $\mathrm{R} \$$ 4.500,00. Para o PAA Leite, a Compra Direta e a Formação de Estoque o limite anual passou para $\mathrm{R} \$ 8.000,00$, sendo que no PAA Leite há um limite semestral de $\mathrm{R} \$ 4.000,00$.
A tabela 1 mostra o número de agricultores fornecedores, valor total das aquisições e importância relativa das diferentes modalidades do Programa de Aquisição de Alimentos (PAA). 
Tabela 1. Número de agricultores fornecedores, valor total das aquisições e importância relativa das diferentes modalidades do Programa de Aquisição de Alimentos (PAA), no ano de 2008.

\begin{tabular}{|c|c|c|c|c|c|c|}
\hline $\begin{array}{c}\text { Modalidade } \\
\text { Ano } 2008\end{array}$ & $\begin{array}{l}\text { Órgão } \\
\text { executor }\end{array}$ & $\begin{array}{c}\text { no de agricultores } \\
\text { familiares } \\
\text { fornecedores }\end{array}$ & $\begin{array}{l}\text { Valor total das } \\
\text { aquisições }(\mathrm{R} \$)^{*}\end{array}$ & $\begin{array}{l}\text { Valor médio } \\
\text { por fornecedor } \\
\text { (R\$)* }\end{array}$ & $\begin{array}{c}\% \text { do } \\
\text { total de } \\
\text { agricultores } \\
\text { fornecedores }\end{array}$ & $\begin{array}{l}\text { Percentual } \\
\text { do valor } \\
\text { total }\end{array}$ \\
\hline Doação Simultânea $^{1}$ & CONAB & 63.062 & 181.746 .957 & $2.882,04$ & 42 & 37 \\
\hline $\begin{array}{l}\text { PAA } \\
\text { Compra Direta Local (CDL) } \\
\text { Municipal }^{2}\end{array}$ & $\begin{array}{c}\text { MDS } \\
\text { e Prefeitura }\end{array}$ & 9.886 & 7.579 .366 & 766,68 & 7 & 2 \\
\hline $\begin{array}{l}\text { PAA } \\
\text { Compra Direta Local (CDL) } \\
\text { Estadual }^{3}\end{array}$ & $\begin{array}{l}\text { MDS e } \\
\text { Governo } \\
\text { Estadual }\end{array}$ & 16.283 & 32.269 .830 & $1.981,81$ & 11 & 7 \\
\hline PAA Leite ${ }^{3}$ & $\begin{array}{l}\text { MDS e } \\
\text { Governo } \\
\text { Estadual }\end{array}$ & 30.584 & 178.570 .863 & $5.838,70$ & 21 & 36 \\
\hline Formação de Estoque $^{1}$ & CONAB & 14.067 & 46.500 .848 & $3.305,67$ & 10 & 9 \\
\hline Compra Direta $^{1}$ & CONAB & 13.494 & 44.681 .634 & $3.311,22$ & 9 & 9 \\
\hline Total & & 147.376 & 491.349 .498 & $3.333,99$ & 100 & 100 \\
\hline
\end{tabular}

Fonte: Matriz de Informações Sociais/Ministério do Desenvolvimento Social (MDS) e tabulações realizadas pelas autoras com dados repassados pela Companhia Nacional de Abastecimento (CONAB) e pelo MDS.

* Em 2008, a cota anual máxima de entrega por família que tenha DAP (Declaração de Aptidão ao Pronaf) era de R $\$ 3.500,00$ para todas as modalidades, exceto o PAA Leite, para o qual esse limite era semestral, sendo R\$7.000,00 o teto anual.

${ }^{1}$ Totais de recursos do MDS e do Ministério do Desenvolvimento Agrário (MDA) - Dados da CONAB, totalizados pela pesquisa.

${ }^{2}$ Compra Direta Local Municipal - dados da Matriz de Informações Sociais do portal eletrônico do MDS, consulta em março/2010.

${ }^{3}$ Compra Direta Local Estadual - dados consolidados pela pesquisa, a partir dos dados desagregados enviados pelo MDS. Há diferenças em relação às totalizações realizadas pelo próprio Ministério ${ }^{13}$.

\section{AS MULHERES NO PAA}

A primeira etapa desta pesquisa consistiu num levantamento quantitativo da participação das mulheres nas diferentes modalidades do PAA, a partir dos nomes e dos CPFs (Cadastros de Pessoa Física) dos(as) agricultores(as) fornecedores(as) que constam nos contratos. Os dados foram disponibilizados pelo MDS e pela CONAB, para o ano de 2008. Nos contratos consta o número da DAP, o nome e o número do $\mathrm{CPF}$ de quem forneceu ao programa. Ou seja, embora as DAPs incluam dois titulares (o marido e a mulher), os pagamentos do fornecimento ao PAA (e os contratos) são feitos em nome de uma só pessoa, identificada por seu CPF. Todos os dados quantitativos de participação de mulheres no PAA aos quais estaremos nos referindo correspondem a mulheres agricultoras familiares cujos nomes constam formalmente nos contratos do PAA e que, consequentemente, recebem o pagamento no seu nome e/ou na sua conta corrente.

Os resultadosapontaram,emnívelnacional,um baixo percentual de mulheres constando formalmente nos contratos. As modalidades com maior percentual foram as de Compra Direta com Doação Simultânea: a Doação Simultânea, operacionalizada pela CONAB, com 28\% de mulheres, o PAA CDL Municipal, com $27 \%$ de mulheres e o PAA CDL Estadual, com $29 \%$ de mulheres. E a modalidade com menor percentual de mulheres foi a Compra Direta, com 13\% de Mulheres, conforme pode ser visto na Tabela $2^{12}$.

${ }^{12}$ Não há diferenças significativas entre os valores médios acessados por mulheres e por homens; os percentuais de números de mulheres e de valor acessado pelas mulheres são, portanto, muito próximos. 
Tabela 2. Número de fornecedores e percentual de Cadastros de Pessoa Física (CPFs) de mulheres entre os fornecedores, nas diferentes modalidades do Programa de Aquisição de Alimentos (PAA) operacionalizadas pela Companhia Nacional de Abastecimento (CONAB) e pelo Ministério do Desenvolvimento Social (MDS).

\begin{tabular}{|c|c|c|c|c|}
\hline Modalidade & Ano & Responsável pela execução & $\begin{array}{l}\text { no total de famílias } \\
\text { agricultoras } \\
\text { fornecedoras } \\
(=100 \%)\end{array}$ & $\begin{array}{l}\% \text { de CPFs de } \\
\text { mulheres nos } \\
\text { contratos }\end{array}$ \\
\hline CPR $^{1}$ Doação Simultânea & 2008 & CONAB & 63.062 & 28 \\
\hline CDL Municipal $^{2}$ & 2007 & MDS e Prefeitura & 5.975 & 27 \\
\hline CDL Estadual $^{3}$ & 2008 & MDS e Governo Estadual & 16.376 & 29 \\
\hline $\mathrm{CPR}^{4}$ Formação de Estoque & 2008 & CONAB & 14.067 & 16 \\
\hline Compra Direta & 2008 & CONAB & 13.494 & 13 \\
\hline PAA Leite & 2008 & MDS e Governo Estadual & 23.479 & 18 \\
\hline
\end{tabular}

Fonte: Companhia Nacional de Abastecimento (CONAB)/Superintendência da Agricultura Familiar (SUPAF)/Gerência de Acompanhamento e Controle das Ações da Agricultura Familiar (GECAF); Ministério do Desenvolvimento Social e Combate à Fome (MDS)/Secretaria Especial de Segurança Alimentar (SESAN). Elaboração das autoras.

${ }^{1}$ Compra da Agricultura Familiar com Doação Simultânea (CPR Doação).

${ }^{2}$ Compra Direta Local (CDL) Municipal - Totais parciais: faltaram dados de 29 municípios.

${ }^{3}$ Compra Direta Local (CDL) Estadual - Há diferenças significativas entre as totalizações feitas pelo MDS, divulgadas na Matriz Social e as totalizações feitas a partir dos dados desagregados. Segundo os gestores, devem-se ao fato de alguns contratos feitos num ano serem executados em outro e poderem constar em anos diferentes. Pelos dados da Matriz Social, seriam 34.500 famílias.

${ }^{4}$ Formação de Estoque pela Agricultura Familiar (CPR Estoque).

A desagregação dos dados mostrou uma variação considerável nos percentuais de mulheres que constam nos contratos entre grandes regiões, Estados e Municípios, não permitindo extrair conclusões sobre as causas das diferenças nos percentuais ${ }^{13}$. A indicação de que a maior diversidade de produtos abrangidos pela modalidade Doação Simultânea favoreceria a participação das mulheres nem sempre foi confirmada pelos dados quantitativos, porque houve, em vários casos, baixos percentuais de mulheres em produtos considerados como tipicamente "das mulheres", como, por exemplo, bolos, doces e conservas. Voltaremos a este aspecto posteriormente.

A única variável que se mostrou coerente, mesmo nos níveis mais desagregados, foi a de renda, com maiores percentuais médios de mulheres nas faixas mais baixas de renda, estimadas a partir do enquadramento no PRONAF.

Embora se saiba que não existe uma correspondência exata entre o CPF que consta

\footnotetext{
13 As variações entre as porcentagens de Cadastros de Pessoa Física (CPFs) de mulheres ocorrem também dentro do próprio município, entre as organizações que acessaram ao programa (inclusive vendendo o mesmo produto) ou até em diferentes contratos feitos pela mesma associação ou cooperativa. Ver relatórios originais da pesquisa (Siliprandi \& Cintrão, 2009 e 2010).
}

no contrato e a pessoa que efetivamente forneceu ao programa ${ }^{14}$, consideramos que o levantamento quantitativo serve para dar uma dimensão da participação formal das mulheres no Programa, indicando tendências e questões a serem observadas.

$\mathrm{Na}$ tabela 3 foram reunidos os resultados relativos ao número de fornecedores e percentual de cadastros de pessoa física (CPFs) de mulheres entre os fornecedores ( diferentes modalidades do Programa de Aquisição de Alimentos- PAA) operacionalizadas pela Companhia Nacional de Abastecimento (CONAB) e Ministério do Desenvolvimento Social (MDS).

\footnotetext{
${ }^{14}$ A pesquisa confirmou que tanto há casos de homens que utilizam CPFs das suas esposas para acesso ao PAA, quanto de mulheres que acessam o PAA com o CPF dos maridos (mais comum). Também há notícias de que podem ser utilizados CPFs de outras pessoas que não as que efetivamente forneceram, por diferentes razões. Na entrega dos produtos ao Programa, também pode haver substituições de fornecedores, de quantidades e mesmo de tipo de produto em relação ao contrato inicial (do qual os dados foram extraídos), motivadas por mudanças na produção em relação ao previsto/planejado.
} 
Mulheres no PAA. Siliprandi e Cintrão

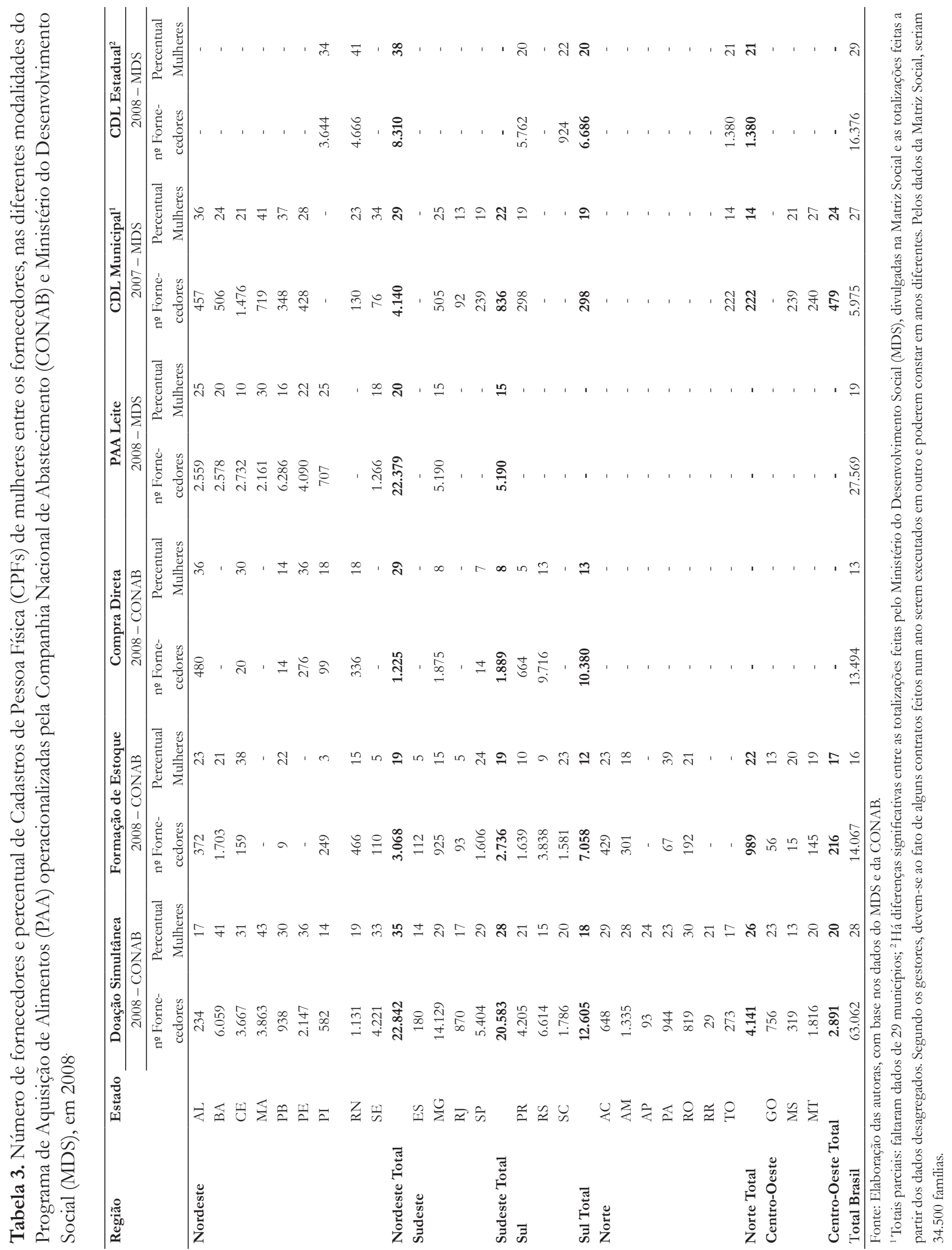


Os dados quantitativos foram complementados por estudos de caso, de caráter qualitativo, nos quais foram visitadas organizações participantes do Programa e entrevistados gestores públicos, agricultoras fornecedoras, representantes dos movimentos de mulheres, organizações não-governamentais, associações, cooperativas e movimentos sociais rurais.

Foram realizados quatro estudos de caso, cada um em um Estado diferente, buscando abranger diferentes regiões do País, diferentes modalidades e situações diferenciadas de participação de mulheres. Em cada Estado o foco principal foi uma modalidade, mas se coletou informações sobre as demais. No Rio Grande do Sul e no Maranhão o foco foram as modalidades de Compra Direta com Doação Simultânea; em Minas Gerais, o PAA Leite; e na Bahia, a modalidade Formação de Estoque.

Os estudos de caso procuraram responder às seguintes questões: por que o $\mathrm{PAA}$ não está atingindo formalmente mais mulheres, em suas várias modalidades de operação? Em que condições as mulheres estão acessando o Programa e o que facilita ou dificulta esse acesso, seja individualmente, seja em grupos organizados? Qual o significado dos percentuais de CPFs de mulheres? Qual a relação entre percentual de mulheres que constam nos contratos e a participação efetiva das mulheres no programa? Qual a importância da participação formal das mulheres no programa, ou seja, que diferença faz para as mulheres o nome delas (e seus CPFs) constarem formalmente dos contratos? A análise foi feita a partir de diferentes pontos de vista: das normas e procedimentos de acesso ao Programa; do conhecimento das mulheres sobre essas normas e do seu grau de organização em relação às questões de comercialização; e do ponto de vista da configuração das famílias rurais, verificandose a existência ou não de um ambiente favorável à autonomia das mulheres. Buscou-se também verificar as diferenças entre as condições de participação das mulheres: individual, em grupos exclusivamente de mulheres ou em grupos mistos (homens e mulheres).

Os estudos qualitativos indicaram que há um conjunto de fatores que interferem no percentual de mulheres que têm seu nome nos contratos, o que faz com que a leitura dos dados quantitativos não seja automática e possa ter distintos significados. Uma primeira questão trazida pelos estudos de caso foi que a participação formal de mulheres no programa - indicada pelo percentual de mulheres que aparece nos contratos do PAA - subestima a real participação das mulheres no Programa, especialmente nas modalidades de Compra Direta com Doação Simultânea, mesmo sendo essas as em que aparecem os maiores percentuais de mulheres.

\section{ELEMENTOS QUE FAVORECEM UMA MAIOR PARTICIPAÇÃO DAS MULHERES NO PAA}

Sem dúvida um dos fatores que influencia para que haja um maior percentual de mulheres nas modalidades de Compra Direta com Doação Simultânea é a grande diversidade e o tipo de produtos abrangidos.

Conforme apontado por vários estudos, há algumas linhas gerais que "orientam" a divisão de trabalho na agricultura familiar, com as mulheres se concentrando nos trabalhos chamados reprodutivos (e voltados para o autoconsumo) e os homens nos produtivos (voltados para a geração de renda). Quando se encontram fora do seu lugar de domínio, o trabalho realizado, seja por homens ou por mulheres, é considerado uma ajuda, um "não-trabalho"15 [2-6,10,40-46].

O fato é que, em todas as unidades familiares de produção, há produtos e tarefas identificados como sendo responsabilidade dos homens ou das mulheres, que serão colocados em determinados mercados e receberão valorizações diferenciadas. Em geral, os produtos voltados para o autoconsumo, que estão sob responsabilidade das mulheres, costumam ter pouco ou nenhum acesso ao mercado, tendo o excedente trocado ou oferecido a vizinhos e parentes, ou simplesmente "perdido". Os produtos considerados "comerciais" ou "de renda" são em geral responsabilidade dos homens, ainda que as mulheres trabalhem efetivamente para a sua produção. Em geral, as atividades de comercialização e o uso dos recursos auferidos com a venda desses produtos

\footnotetext{
${ }^{15}$ É assim que os agricultores interpretam a participação dos homens em atividades domésticas, por exemplo. Magalhães (2005) aponta que no Paraná se considera que os homens "ajudam” em tarefas como lavar louça ou arrumar a casa e "ajudam" as mulheres na ordenha das vacas. As mulheres, por outro lado, "ajudam" os homens na lavoura, no manejo do pasto e na manutenção das cercas, atividades consideradas masculinas. A atribuição de responsabilidades pode ser ainda mais complexa. Naquele Estado, quando o serviço na lavoura é a produção de alimentos para os animais, como milho ou produtos para silagem, a atividade pode ser considerada feminina, mas dificilmente as mulheres se envolvem na produção de soja, mesmo na condição de ajudantes.
} 
fogem ao controle das mulheres.

As modalidades do PAA de Compra Direta com Doação Simultânea, por permitirem a compra de uma gama diferenciada de produtos alimentares, vêm propiciando a criação de um mercado "institucional", com preços justos, para os produtos tradicionalmente vinculados à esfera feminina, ao "autoconsumo", à "subsistência" e ao "quintal", cultivados em áreas próximas à casa, ou em áreas não aproveitadas para cultivos comerciais. Alguns deles já eram vendidos pelas mulheres, mas em escala menor e com mais dificuldades, como as aves e os ovos, as hortaliças (bastante incluídas no PAA e em vários casos estimuladas por ele), e as frutas $^{16}$. Há, ainda, casos em que o PAA cria (ou recria) formas de escoamento para produtos que estavam à margem dos mercados hegemônicos, que estavam sendo deixados de produzir por muitas famílias, como vários tipos de abóbora, batatas-doce, carás, inhames. Os exemplos são inúmeros, dado que as modalidades de Compra Direta com Doação Simultânea abrangem mais de 300 produtos diferentes em nível nacional, com marcantes variações regionais.

O PAA abre ainda uma importante perspectiva para venda de produtos processados, tradicionalmente utilizados no consumo da casa ou vendidos em pequenas quantidades e que permitem agregação de valor aos produtos da agricultura familiar. A lista destes produtos é bastante extensa e reflete a cultura e os produtos de cada região. As scbimias (geleias de frutas), conservas, cucas, massas, pães e biscoitos feitos com trigo no Sul; diversos doces de frutas, biscoitos de polvilho e de fubá, além dos queijos e dos pães de queijo em Minas Gerais; os bolos de macaxeira, de tapioca, de mesocarpo de babaçu, a massa puba ou massa de macaxeira (para fazer mingau ou bolo) no Maranhão e em outros Estados do Nordeste ${ }^{17}$.

Adicionalmente, essas modalidades do PAA abrem oportunidade comercial para um conjunto de produtos do extrativismo, que em grande parte são

\footnotetext{
${ }^{16}$ Houve vários depoimentos de mulheres que disseram ter começado a identificar (em geral com ajuda de técnicos ou de gestores do programa) produtos passíveis de venda no seu próprio quintal, como limão, manga e outras frutas que antes "se perdiam".

${ }^{17}$ É interessante notar que alguns produtos processados permitem aproveitar, simultaneamente, um conjunto de produtos da agricultura familiar, processados e não processados, muitos deles também sob responsabilidade das mulheres. Por exemplo, no Nordeste, os bolos, biscoitos e pães, que aproveitam o ovo, o leite, a manteiga e a mandioca (ou derivados, como massa de puba ou polvilho), bem como o açúcar mascavo.
}

atribuições das mulheres. Na maioria dos casos, os produtos extrativos passam por algum processamento antes de serem entregues ao PAA. Citando apenas os exemplos dos Estados visitados, temos os produtos do Cerrado em Minas Gerais (o pequi e frutas como cagaita, coquinho azedo, panã, etc., fornecidas sob a forma de polpas), os mariscos (entregues já limpos e processados) e os produtos do babaçu no Maranhão (em especial o mesocarpo, pois o azeite ainda é pouco incluído), doces e sucos de frutas nativas no Rio Grande do Sul (ananá, butiá) e de frutas da Caatinga no Nordeste (umbú, maracujá, goiaba).

Em todos estes casos, as modalidades de Compra Direta com Doação Simultânea têm um grande potencial de serem "apropriadas" pelas mulheres rurais, seja individualmente ou através de grupos produtivos $^{18}$. Em quase todos os tipos de produtos citados anteriormente, mas em especial nos produtos processados, nos casos em que há uma continuidade ao longo dos anos, o PAA vem contribuindo para uma progressiva melhoria desse processamento e adequação às exigências sanitárias, permitindo às famílias ou aos grupos produtivos acessarem outros mercados ${ }^{19}$.

Os efeitos do PAA são bastante positivos, no sentido de favorecer a produção de alimentos nas pequenas propriedades, reforçando a segurança alimentar não apenas dos que recebem os alimentos, mas também dos próprios produtores, aspectos também ressaltados por outros estudos ${ }^{20}[30,34,37,38]$. Como o cuidado com a alimentação está ligado à "esfera feminina", há um

\footnotetext{
${ }^{18}$ Será interessante verificar se com a criação desses novos mercados pelo PAA pode haver uma "mudança no comando", como observado em alguns produtos, que, na medida em que passam a ser valorizados em mercados mais estruturados e obtêm melhores preços ou garantias de escoamento, deixam de estar sob responsabilidade das mulheres, e passam a ser gerenciados e comercializados pelos homens. Isso foi observado em outros estudos com a produção de leite, hortaliças e frutas, processamento de alimentos (doces, conservas). Uma contraposição a essa tendência ocorre quando, concomitantemente às melhorias de mercado, a organização das mulheres é fortalecida.

${ }^{19}$ Os projetos do PAA proporcionam mercado e um preço garantido por um período de um ano, estimulando a produção em maior escala, o aprendizado sobre o mercado e o reinvestimento em equipamentos. Favorecem também a adequação progressiva dos empreendimentos às normas sanitárias municipais, estaduais e federais.

${ }^{20}$ Ver, por exemplo, a dissertação de mestrado de Claudio Becker, indicada na bibliografia; além dos textos de Grisa (2009), Becker et al. (2009), entre outros, que trazem dados sobre como o PAA estimulou a produção para o autoconsumo na Região Sul. No Nordeste, destaca-se o trabalho de Zimmermann \& Ferreira (2008), que analisou o caso de Mirandiba (PE), com resultados semelhantes.
} 
envolvimento especialmente solidário das mulheres com o fornecimento dos alimentos à população beneficiária, o que também leva à preocupação com a saúde e a qualidade da oferta de alimentos. Isso se reflete também na busca de redução do uso de agrotóxicos, em especial no caso de alimentos voltados para crianças (creches e escolas) e, no Rio Grande do Sul, vem reforçando o que é chamado de "transição para a agroecologia", que, em vários casos, tem nas mulheres as principais incentivadoras ${ }^{21}$. Isso é favorecido pelo fato do PAA pagar um adicional de $30 \%$ a produtos orgânicos ${ }^{22}[37,38]$.

O fato de envolverem um grande número de produtos "sob responsabilidade das mulheres" certamente influencia para que os percentuais de mulheres nos contratos (CPFs de mulheres) sejam maiores nas modalidades de Compra Direta com Doação Simultânea em relação a outras modalidades. Uma contraposição pode ser vista na modalidade Compra Direta da Agricultura Familiar, por exemplo, que é restrita a poucos produtos, vários deles resultados de lavouras anuais em geral "sob responsabilidade dos homens". Nessa modalidade, os percentuais de CPFs de mulheres nos contratos é bem menor.

O caso do PAA Leite, também com baixos percentuais de CPFs de mulheres, é ilustrativo de um produto que é tido, nas regiões onde esta modalidade opera, como uma atividade essencialmente pertencente à esfera masculina. No Nordeste e no Norte de Minas Gerais, argumentos como a necessidade de força física e virilidade na lida com os animais, em especial a ordenha, são constantemente evocados para justificar o pertencimento do leite ao universo masculino. A ordenha chega a ser vista como "perigosa" para (e pelas) mulheres ${ }^{23}$. No entanto, a análise da literatura sobre a divisão de trabalho e os papéis sociais de gênero na pecuária leiteira aponta que no Sul do Brasil a ordenha e o cuidado com as vacas de leite são

\footnotetext{
${ }^{21}$ No Território da Cidadania visitado no Rio Grande do Sul, o PAA é apontado, em conjunto com outras iniciativas, tais como as feiras ecológicas e as experiências de venda para a alimentação escolar, como um programa que vem auxiliando as famílias a deixarem o plantio de culturas que utilizam muitos agrotóxicos, como o fumo.

22 Por outro lado, em muitos casos, apesar de os produtos fornecidos ao PAA serem isentos de produtos químicos, não são vendidos como orgânicos, seja por desinformação dos envolvidos, seja por dificuldades de acesso à certificação. Esse é o caso de quase todos os produtos extrativistas.

${ }^{23}$ Nas entrevistas com mulheres no Norte de Minas apareceram referência a ter "medo de tirar leite", bem como uma certa admiração pelas mulheres que trabalhavam na ordenha, que eram conhecidas e apontadas como exceção.
}

atividades pertencentes à esfera feminina. Também na comercialização e na produção de queijos os papéis de gênero podem ser invertidos nas diferentes regiões, sendo responsabilidade das mulheres em algumas regiões e dos homens em outras. O caso da produção leiteira acaba sendo um exemplo bastante ilustrativo de como a divisão de trabalho entre os sexos é um processo cultural e sujeito a variações históricas ${ }^{24}$. O estudo de caso no Norte de Minas Gerais apontou que, mesmo famílias nas quais as mulheres eram as responsáveis por todos ou quase todos os trabalhos na atividade leiteira, incluindo a ordenha, os contratos permaneciam em nome dos maridos. $\mathrm{E}$ as mulheres visitadas cujos nomes constavam nos contratos não eram as responsáveis principais pela atividade: este havia ficado em seu nome por algum impedimento legal do marido ou dos filhos homens, ou então por opção do casal (em geral do próprio marido). Vale observar ainda que na atividade leiteira, há, para além da ordenha, um conjunto de atividades executadas pelas mulheres (esposas e filhas), consideradas como "ajuda" aos homens (que são os responsáveis) e que ficam invisibilizadas e de uma forma geral as mulheres estão excluídas do gerenciamento desta atividade, que tem um impacto significativo na sua vida ${ }^{25}$. A representação social e cultural do trabalho no leite como pertencente à esfera masculina na região de operação do PAA Leite parece ser um dos fatores principais que explica a não formalização da participação das mulheres nesta modalidade, mesmo nos casos em que ela é a principal responsável, tendo implicações na invisibilidade do seu trabalho e na sua exclusão do gerenciamento dessa atividade ${ }^{[4,5,40-42,45,47-50]}$.

\footnotetext{
${ }^{24}$ A literatura sobre a divisão sexual do trabalho no leite é quase inexistente no Nordeste. Na região Sul há vários trabalhos, inclusive apontando variações históricas: quando a atividade leiteira deixa de ser prioritariamente para o consumo e assume maior tecnificação e importância econômica, ela tende a passar para a responsabilidade masculina. Ver Menasche \& Escher (1996), DESER (1996), De Grandi (1999) e Magalhães (2005).

${ }^{25}$ Mesmo quando não envolvidas diretamente na ordenha, as mulheres despertam antes dos homens para preparar e levar o café para os maridos no estábulo, estão diretamente envolvidas nos procedimentos de limpeza dos equipamentos e, em muitos casos, são as responsáveis pelo processamento do leite. No Norte de Minas Gerais, algumas mulheres entrevistadas (de produtores menores, antes não atendidos por laticínios), observaram que o PAA Leite as aliviou do trabalho desgastante de produção e venda de queijo (que naquela região, quando em pequena escala é, em geral, atribuição das mulheres). No entanto, o caráter do trabalho de campo não permitiu avaliar que impacto pode ter para elas deixarem de ter o dinheiro da venda do queijo.
} 


\section{A INVISIBILIDADE E O "ANONIMATO" DAS MULHERES NO PAA}

Os estudos de caso apontaram que, em especial nas modalidades de Compra Direta com Doação Simultânea, embora seja bastante significativa a inclusão de produtos "da esfera feminina" no programa, o percentual de mulheres formalmente registradas como fornecedoras, ou seja, o percentual de nomes e CPFs de mulheres titulares de DAP nos contratos está aquém da proporção de força de trabalho feminina empregada na sua produção. No Rio Grande do Sul, por exemplo, apenas 15\% dos contratos da modalidade Doação Simultânea estão em nome das mulheres, apesar de sua forte presença na produção. Parte do "anonimato" das mulheres foi atribuída à "questão cultural"26, que "esconde" a mulher no espaço doméstico, sendo o homem o "representante da família" nos espaços públicos. $\mathrm{O}$ argumento é que, apesar de estarem "anônimas" e "escondidas", as mulheres que participam do PAA têm poder de decisão no espaço privado, mas nos espaços públicos a autoridade é dos homens, que representam formalmente a família.

Com relação ao uso dos recursos, a pesquisa preocupou-se em analisar se fazia diferença para as mulheres que seus nomes constassem formalmente nos contratos e que o pagamento saísse em nome delas.

Embora de maneira geral, como aponta a bibliografia a respeito do programa, toda a família seja amplamente beneficiada pelo PAA, e ainda que sejam frequentes afirmações de que "tanto faz" em nome de quem é feito o pagamento do programa, há fortes indicativos de que é comum haver uma privação da mulher das decisões sobre o uso do dinheiro e que em muitos casos é muito importante para as mulheres que seu trabalho tenha uma remuneração específica, separada da do homem. Ter seu próprio dinheiro, não precisar "pedir ao marido" ou "prestar contas" dos gastos é bastante valorizado por muitas mulheres ${ }^{27}$. Algumas entrevistadas se referiram ao período em que não tinham autonomia financeira como "um

\footnotetext{
${ }^{26}$ Embora muitas vezes se referissem a regiões onde predominam determinadas etnias, em outras a afirmação era do contrário, ou seja, o argumento de que "é cultural" parece um coringa que vale para todas as situações.

${ }^{27}$ Também para os jovens rurais essa questão de acesso e controle dos recursos financeiros é importante e influencia na sua decisão sobre sair ou não da propriedade. Ver Magalhães (2005).
}

inferno", "uma humilhação", por ficarem sujeitas ao controle do marido.

Reforçando essas indicações, foram comuns menções à Aposentadoria Rural e à Bolsa Família como exemplos de políticas que propiciaram às mulheres $\mathrm{O}$ acesso direto a recursos monetários e, porque não dizer, um reconhecimento da sua cidadania, com sua saída do "anonimato" [51]. Por exemplo, Rego (2008, citando Pereira et al., 2009) ${ }^{[52,53]}$ observa o sentido emancipatório presente no fato da titularidade do benefício do Bolsa Família ter sido colocada na mão das mulheres ${ }^{28}$. As mulheres têm diferentes prioridades de compra e ter acesso direto aos recursos possibilita um exercício de negociação com o parceiro no domicílio sobre essas prioridades. Muitas beneficiárias ressaltaram também a sua maior visibilidade na sociedade e o aumento do poder de decisão fora do domicílio ${ }^{29}$. As autoras argumentam que as possibilidades de autonomização mínima das mulheres abertas pelo Programa Bolsa Família transcenderiam o nível puramente monetário, refletindo também nas possibilidades de expressão e direito a vOz na sociedade, abrindo caminho para o reconhecimento dos direitos de cidadania das mulheres ${ }^{[52]}$.

Depoimentos de lideranças de mulheres ouvidas por esta pesquisa apontaram que a questão do acesso ao dinheiro e às decisões sobre seu uso é difícil de ser explicitada pelas mulheres rurais por se tratar de questões íntimas das famílias: nas reuniões de grupos de mulheres, quando alguém comenta algo, às vezes as outras se "atrevem" também a se colocar. Foram citados casos em que as mulheres comentam o assunto em conversas confidenciais com as lideranças ou que, somente ao participar de movimentos que discutem a questão de gênero, passaram a "desnaturalizar" sua situação, antes tida como "normal" e a se dar conta de que o acesso direto aos recursos e à decisão sobre seu uso é importante na sua vida e é um direito. Houve referências ao fato de que um marido "bom" é aquele que "compra as coisas para a casa" para deixar a mulher satisfeita e ainda "dá" um dinheirinho para a mulher gastar com o que quiser (mesmo em

${ }^{28}$ Os depoimentos de mulheres citados pelas autoras se aproximam muito dos ouvidos no caso das mulheres que têm seu nome nos contratos do PAA.

${ }^{29} \mathrm{O}$ fato de possuírem o cartão, de deslocarem-se para receber o pagamento, negociarem com comerciantes locais a abertura de créditos foram apontadas pelas beneficiárias como mudanças ocorridas após ingresso no Programa Bolsa Família. Mesmo assim, não se verificou uma redução automática das desigualdades de gênero e dos padrões tradicionais de distribuição de papéis entre mulheres e homens no âmbito doméstico. 
casos em que a mulher trabalha de igual para igual, como nas hortaliças, por exemplo). Isso indica que há um conjunto de maridos "não tão bons", que dão outras prioridades ao dinheiro. Foram ainda comuns as referências a constrangimentos passados pelas mulheres por ter que pedir dinheiro aos maridos para a compra de roupas íntimas ou outros objetos de uso pessoal, bem como para os gastos com os filhos, incluindo gastos com educação ${ }^{[4]}$.

\section{FATORES QUE FAVORECEM A “INVISIBILIDADE" OU O “ANONIMATO” DAS MULHERES NO PAA: A QUESTÃO DA DOCUMENTAÇÃO E O "MACHISMO" DAS LEIS}

Os estudos de caso apontaram que há um conjunto de fatores relacionados com a documentação para a formalização dos contratos, que dificulta uma maior participação direta das mulheres, de forma que os seus nomes apareçam formalmente nos projetos. Uma das explicações para o fato dos projetos do PAA estarem no nome dos homens, mesmo nos casos em que as mulheres são as principais responsáveis e a principal força de trabalho dos produtos entregues, é o fato da documentação em geral estar no nome do marido, considerado como o "representante da família".

Por outro lado, é muito frequente (entre agricultores, técnicos, agentes públicos, representantes sindicais e dirigentes de cooperativas) a interpretação de que o homem é o "titular" da DAP, sendo as mulheres "dependentes" e que o projeto do PAA precisa ser feito em nome "do" titular. Conforme comentado anteriormente, a DAP é um documento "da família" que tem como objetivo comprovar, junto ao Governo Federal, o enquadramento nos critérios da Agricultura Familiar para estar apta a receber os benefícios direcionados a essa categoria social. Isso se deve ao fato de que quando a DAP foi criada, o formulário de preenchimento continha, na primeira parte, a "identificação do(a) Agricultor(a) Familiar" na qual constava apenas um nome (que teoricamente poderia ser do esposo ou da esposa, mas na quase totalidade dos casos consta o nome do homem). E somente ao final, na segunda parte da DAP, denominada "Informações Complementares", eram solicitados os dados do cônjuge. Com a intervenção da Assessoria em Gênero, Raça e Etnia do MDA, respondendo a solicitações dos movimentos de mulheres, na safra 2004/2005 foram incluídos os dois nomes (marido e esposa) no início do documento, colocados como $1^{\circ}$ Titular e $2^{\circ} \operatorname{Titular}^{30}$. Como essa denominação também poderia ser interpretada como uma hierarquia, houve uma terceira modificação, na safra 2005/2006, deixando um espaço para os titulares ${ }^{[54]}$. Mas o primeiro modelo deixou marcas e nos estudos de caso apareceram inúmeras menções ao fato "do titular" da DAP ser o homem31.

Um problema geral para o acesso das mulheres rurais às políticas públicas ( $\mathrm{e}$, porque não dizer, a uma cidadania plena), do qual a titularidade da DAP é apenas uma parte, refere-se à falta de documentação pessoal e profissional. A falta de documentos básicos, como identidade e CPF, apareceu nos estudos de caso como uma realidade ainda bastante presente, apesar dos esforços realizados pelo MDA através do Programa Nacional de Documentação da Trabalhadora Rural $(\text { PNDTR })^{32}$.

A documentação da terra é outro impeditivo: foi corrente em campo a interpretação de que a DAP (e o projeto do PAA) precisam estar no mesmo nome de quem tem a documentação da terra, que, de uma forma geral, é o homem. Até muito recentemente (2003) apenas o nome do marido constava na documentação dos assentamentos de Reforma Agrária, por exemplo. Por meio de várias lutas os movimentos de mulheres conseguiram a inclusão dos

\footnotetext{
${ }^{30}$ O Manual do Cadastrador da DAP - Declaração de Aptidão ao PRONAF (Programa Nacional de Fortalecimento à Agricultura Familiar) destaca que a dupla titularidade é uma novidade, que "permite a identificação de cada um dos membros do casal responsável pela manutenção da unidade familiar". E observa que "não existe precedência entre quaisquer dos titulares no domínio da titularidade da DAP” (SAF/MDA, Manual da DAP 2004/2005).

${ }^{31}$ Um exemplo é o fato do modelo do formulário da DAP que constava no Manual de Operações da Companhia Nacional de Abastecimento (CONAB) de 2008 ser ainda da primeira versão (Ver Título 27 - CDAF - Documento 1 - Anexo 1 - Declaração de Aptidão ao PRONAF Comunicado CONAB/MOC no 020 de 15/08/2008). Nos estudos de caso, outra interpretação errônea que apareceu foi do termo "agricultores pronafianos" (como exigência para o acesso ao PAA, de ter DAP) como sendo agricultores que tomaram empréstimos do PRONAF.

${ }^{32}$ Mesmo no Rio Grande do Sul, Estado onde há uma maior formalização dos contratos e maior escolarização na população rural, uma das entrevistadas mencionou que encontro realizado com mulheres rurais no território da cidadania visitado constatou a existência de várias mulheres sem documentação pessoal. No Maranhão, houve menção ao fato de que os mutirões de documentação realizados recentemente no Estado pelo Programa Nacional de Documentação da Trabalhadora Rural (PNDTR), especialmente em áreas de assentamentos, haviam sido importantes para o acesso das mulheres rurais a documentação pessoal.
} 
seus nomes nos títulos ${ }^{33}$, mas é considerado "cultural" que os documentos e contratos de terra continuem apenas em nome dos maridos.

Outro documento necessário ao PAA, do qual as mulheres tendem a ser excluídas, são as notas fiscais dos produtores rurais. No Rio Grande do Sul, a inclusão do nome das esposas no "bloco de notas" foi uma conquista das agricultoras na luta pelo seu acesso aos direitos previdenciários, para comprovação da profissão, dado que, em seus documentos profissionais, essas constavam como "trabalhadoras domésticas" ou "do lar". Naquele Estado, a inclusão do nome do casal (marido e mulher) nos blocos de nota é comum, mas seria necessário verificar como isso se dá em outros Estados. Um dos gestores do PAA Leite de Minas Gerais, ao ser indagado se naquele Estado era possível constar o nome da mulher no "cartão do produtor", para a emissão da nota fiscal no nome dela, observou, ao ficar em dúvida: "será que a legislação pode estar sendo machista?"34. A necessidade de notas fiscais é uma das dificuldades para a prestação de contas no caso da Modalidade Doação Simultânea, que vem sendo resolvida de forma diferenciada em cada Estado, influenciada pelas diferentes exigências das Secretarias Estaduais de Fazenda ${ }^{35}$. Se esses documentos já são um problema no caso dos agricultores homens, mais ainda no caso das mulheres. O acesso à conta bancária é outro fator de dificuldade, com casos de funcionários de bancos que discriminam e colocam obstáculos à abertura de contas correntes pelas mulheres rurais.

\footnotetext{
${ }^{33}$ A Portaria 981 do Instituto Nacional de Colonização e Reforma Agrária (INCRA), de outubro de 2003, declara obrigatória a titularidade em nome da mulher e do homem. A Instrução Normativa no 38, publicada pelo INCRA em março de 2007 alterou os procedimentos e instrumentos, estabelecendoa obrigatoriedade de inclusão da mulher e do homem, independente de estado civil, em todos os cadastros e sistemas de informação do INCRA, além de mudar a sistemática de classificação dos beneficiários da reforma agrária, priorizando as mulheres chefes de família.

${ }^{34}$ Em Minas Gerais perguntamos a várias pessoas se era possível incluir o nome da mulher, ao lado do marido, no cartão "do" produtor, e ninguém sabia nos informar. Parece que também nesse caso a documentação da terra estar no nome da mulher é importante. As instruções para emissão desse cartão, no site da Secretaria da Fazenda, não deixam isso claro; no entanto, o termo utilizado (cartão do produtor) está sempre no masculino.

35 A ausência de notas fiscais de produtores rurais (tanto individuais quanto por parte das organizações de agricultores/as) é apontada como uma das dificuldades na formalização do PAA. No Maranhão, por exemplo, para superar este problema a CONAB conseguiu junto à Receita Estadual a emissão por ela própria de uma nota fiscal específica para a modalidade Doação Simultânea. Essa solução havia sido encontrada pela superintendência do Ceará e parece estar sendo adotada em vários Estados do Nordeste.
}

A própria dificuldade de acesso à DAP aparece como problema: além dos problemas existentes para a emissão da DAP em algumas regiões ${ }^{36}$, os critérios de emissão da DAP, ao serem voltados para acesso ao crédito rural, impedem a inclusão das agricultoras urbanas e também criam empecilhos para famílias com membros assalariados, mesmo que os demais tenham na agricultura sua atividade principal e tenham produtos disponíveis para fornecer ao PAA. Em vários desses casos as mulheres são as maiores prejudicadas.

O fato de o PAA estabelecer um limite anual de compras "por DAP”, ou seja, "por família", somado à ausência de normas explícitas a respeito da inclusão de mais de um titular da mesma DAP acabam levando a que os contratos incluam apenas uma pessoa por família, que, conforme mencionado anteriormente, tende a ser o do marido, tido como "chefe da família" e seu representante. A inclusão de um único nome por família é reforçada pelo fato do controle administrativo das cotas máximas de fornecimento ser feito pela soma dos valores entregues por $\mathrm{CPF}$ (e não por DAP). $\mathrm{Ou}$ seja, a inclusão de mais de um CPF por família dificulta o controle da soma das entregas feitas por aquela família.

Outra justificativa apontada para a não inclusão do nome das mulheres formalmente nos contratos seria a maior "facilidade" da pessoa responsável pela parte burocrática de colocar o primeiro nome que consta na DAP (no momento de elaboração do projeto) ou na Nota do Produtor (no momento da prestação de contas). Note-se que em todos os casos citados anteriormente está embutida uma "cultura institucional" (formas de agir de agentes públicos, regulamentos, documentos, etc.) que reforça a "cultura" corrente referente à chefia familiar.

Mesmo sendo essa a prática corrente, diferentes posturas dos(as) gestores(as) e técnicos(as) que acompanham o programa podem estar influenciando na maior ou menor visibilidade das mulheres. Por exemplo, no Rio Grande do Sul, Estado com menores percentuais de mulheres, a prática da CONAB era de exclusão automática da mulher no caso de encontrar o marido e a mulher

\footnotetext{
${ }^{36}$ Embora haja casos bastante diferenciados nas várias regiões, foram apontadas inúmeras dificuldades para a obtenção da DAP (que pode ser emitida por órgãos como INCRA, Empresas de Extensão Rural, como as EMATER, Fundação Nacional do Índio (FUNAI), Colônia de Pescadores, ou mesmo Sindicatos de Trabalhadores Rurais).
} 
(da mesma família/DAP) no contrato ${ }^{37}$. Em Minas Gerais, a CONAB devolvia o projeto e pedia à organização proponente (associação ou cooperativa de agricultores) que indicasse qual dos dois nomes daquela família deveria ser excluído. Já no Maranhão e na Bahia, com maiores percentuais de participação de mulheres, a CONAB procurava identificar qual dos dois (marido ou mulher) estava efetivamente mais envolvido na produção ${ }^{38}$. Em todos os Estados foi voz corrente (em especial por parte das lideranças de mulheres) dizer que, caso seja pedido para excluir um dos dois, a tendência é excluir a mulher. Mesmo onde há organizações fortes de mulheres, também há uma tendência em deixar no nome dos maridos para evitar conflitos, em especial quando o trabalho na produção envolve homens e mulheres de maneira mais equitativa, como muitas vezes acontece na produção de hortaliças para o fornecimento ao programa.

Em todos os estudos de caso apareceram exemplos de estratégias utilizadas pelas mulheres para minimizar sua exclusão do seu acesso direto ao PAA, todos eles subterfúgios que indicam que seria necessária uma individualização das cotas de acesso dos diferentes membros da família. Houve casos, ainda que esporádicos, de comunidades onde operavam simultaneamente as modalidades Doação Simultânea (operacionalizada pela CONAB) e Compra Direta Local Municipal (operacionalizada pela prefeitura), em que as mulheres negociaram para deixar o nome do marido em uma modalidade e incluir o seu nome em outra, para que elas pudessem vender diretamente seus produtos. A mesma prática apareceu em municípios onde famílias que vendem ao PAA estão passando a fornecer para a alimentação escolar, através da nova lei do Programa Nacional de Alimentação Escolar (PNAE), nos quais algumas mulheres negociam com os maridos para que eles fiquem com o recurso das vendas para alimentação escolar (cujo limite é o dobro do PAA)

\footnotetext{
${ }^{37}$ Há naquele Estado uma compreensão corrente, tanto por parte dos gestores das políticas quanto das organizações de agricultores, de que "a família" é a unidade de produção e que "o chefe" da família a representa, de forma que o contrato naturalmente deve estar em nome do marido.

${ }^{38}$ Essa postura também parece estar relacionada com a presença forte do movimento de mulheres (quebradeiras de coco de babaçu no Maranhão, Rede de Produtoras Rurais na Bahia) e com o fato de haver um maior número de chefes de família mulheres e maior migração sazonal de homens para trabalho em outras regiões.
}

e deixem para elas o acesso direto ao $\mathrm{PAA}^{39}$. Em um dos locais visitados, onde havia o PAA Municipal, por desinformação da prefeitura, num primeiro ano foram incluídos os produtos "dos homens" e "das mulheres" da mesma família separadamente. No ano seguinte, ao ser informada que era um limite único por família, a prefeitura corrigiu os contratos e deixou apenas os nomes dos maridos, causando uma revolta e insatisfação geral nas mulheres, que deixaram de produzir algumas hortaliças que estavam sob sua responsabilidade. O presidente da associação desta comunidade, comentando sobre a injustiça desse fato, ponderou:

"Devia de ser como o Bolsa Família, que o governo decide que é no nome da mulher e pronto. (...) Deveria ser determinação, porque nós seres humanos, rege muito a lei. Se não vier a ordem de cima, ninguém vai dar chance para as mulheres. Os homens são muito gananciosos, se tem dinheiro [envolvido], épara eles".

Nos locais onde as mulheres estão mais organizadas, seu poder de negociação e as suas "chances" de serem reconhecidas é maior. Porém, a divisão e a gestão dos recursos ainda são vistas como pertencentes à esfera privada das famílias e é difícil de serem trabalhadas pelas organizações, que, muitas vezes, tendem a evitar maiores conflitos. A referência feita ao Programa Bolsa Família, cujos recursos são obrigatoriamente em nome da mulher, indica a importância que podem ter políticas afirmativas para as mulheres ${ }^{40}$. 
De uma forma geral, o estabelecimento, pelo PAA, de um limite único por família, que desconsidera sua composição e a divisão interna de trabalho, bem como as relações de poder existentes, tende a reforçar a "cultura" patriarcal ou, no mínimo, deixa de contribuir para romper com ela ${ }^{41}$.

\section{OS TIPOS DE ORGANIZAÇÃO FORMAL E VANTAGENS PARA AS MULHERES}

Outro fator que pode favorecer ou desfavorecer a maior participação das mulheres é a forma organizativa envolvida no PAA. É bastante comum que as organizações formais da agricultura familiar, como sindicatos, associações e cooperativas (assim como as organizações religiosas, que muitas vezes foram a origem das demais), tenham apenas um associado por família, em geral o marido, "chefe da família", que representa todos os seus membros. As cooperativas, em especial, são historicamente um espaço de participação masculina, pois foram criadas principalmente para os produtos considerados "comerciais" que estão sob responsabilidade dos homens - leite, feijão, milho, batata, fumo ${ }^{42[5]}$.

Para que mais de uma pessoa da mesma família tenha direito a voto (quando permitido), é,

\footnotetext{
${ }^{41}$ Embora não tenha sido o foco desta pesquisa, em todos os estudos de caso apareceram menções ao fato de que também os jovens, filhos e filhas que moram e trabalham com os pais agricultores, ficam "anônimos" e excluídos do acesso direto ao PAA, situação que em vários aspectos se assemelha às mulheres (esposas). A visão de que na agricultura familiar todos trabalham “juntos” também limita o acesso dos/das jovens à renda do seu trabalho. Há indícios de que a situação seria ainda pior no caso das filhas mulheres. A existência de uma cota única por família acaba sendo injusta ao desconsiderar todas as diferenças de ciclo familiar e de composição da força de trabalho nas famílias. Por exemplo, uma família visitada no Maranhão tinha quatro filhos e filhas solteiros (as) com idades entre 18 e 22 anos que estudavam e trabalhavam com os pais na horta. Esta família tinha direito à mesma cota máxima que outra família, cujos filhos já haviam casado e saído de casa e apenas a mulher trabalhava na horta. A questão da participação dos (as) jovens rurais no PAA mereceria um estudo específico, mas há várias indicações de que o limite único por família também é problema nesses casos.

42 A delimitação dos espaços públicos como sendo um território masculino também traz como consequência uma menor experiência das mulheres com as questões referentes à comercialização - quanto ao funcionamento dos mercados, exigências de apresentação dos produtos, planejamento, logística, financiamento, assistência técnica, etc. Quando elas começam a participar desse mundo, o fazem com muita insegurança, em parte porque se sentem fora do seu lugar social e também por terem medo de estar fazendo dívidas que poderão comprometer o patrimônio da família. Muitas vezes essa participação é ainda mais dificultada pela sobrecarga com o trabalho doméstico, obrigação praticamente exclusiva das mulheres, para a qual nem sempre elas recebem apoio dentro da família, caso queiram se dedicar a outras atividades.
}

em geral, necessário pagar outras cotas-parte ou taxas, com maiores custos para a família. Mas não é somente o pagamento de mais de uma taxa que atrapalha: as propostas de associações individuais dos diferentes membros da família chegam a "chocar as pessoas", que acham que um sistema individual "não prospera" "43. As lutas travadas pelos movimentos de mulheres rurais vêm conseguindo conquistas, em especial no que se refere à filiação aos Sindicatos de Trabalhadores Rurais, utilizada em muitos Estados como comprovação da profissão de agricultora para fins previdenciários. Cooperativas mais recentes, ligadas ao movimento de economia solidária, têm criado regras especiais visando favorecer a participação das mulheres, como é o caso de cotas para mulheres nas suas diretorias, ou possibilidade de filiação de mais de um membro da família sem que seja necessário o pagamento de outra mensalidade ${ }^{44}$.

As mulheres têm maior participação em experiências menores e informais, perfil da maior parte dos grupos produtivos de mulheres. Essa é uma das explicações para um menor percentual de mulheres nos contratos do PAA no Rio Grande do Sul, em que predominam contratos através de cooperativas. Em alguns Estados como o Rio Grande do Sul, em que a Receita Estadual não permite que a comercialização seja feita por associações, acabam sendo priorizadas as cooperativas, o que dificulta a participação das mulheres e é mais um fator explicativo dos baixos percentuais de mulheres naquele Estado. Caso semelhante é visto na modalidade Formação de Estoque, que apresenta baixos percentuais de mulheres e é operada em geral por organizações formalizadas e mais estruturadas, com acesso prévio a mercados.

Essa questão também é sentida na modalidade Doação Simultânea, que exige uma organização formal para encaminhar os projetos. Algumas lideranças femininas consideram que pode não valer a

\footnotetext{
${ }^{43}$ Esse discurso aparece também em outros espaços e regiões e foi muito comum desde quando se criaram políticas específicas para mulheres, tais como o PRONAF-Mulher e a titulação conjunta dos lotes de Reforma Agrária. Em um evento de âmbito nacional, ocorrido em Brasília em 2010, um diretor sindical dos trabalhadores rurais se colocou veementemente contra a ideia de individualização das atividades dentro da unidade familiar. $\mathrm{Na}$ visão dele, no limite, isso levaria a se defender que cada um tivesse a sua DAP, explodindo com o conceito de família como unidade produtiva, o que iria contra o caráter familiar da agricultura familiar.
}

${ }^{44}$ Esse é o caso, por exemplo, da Cooperativa Sul-Ecológica no Rio Grande do Sul, assim como da Cooperativa de Gestão dos Empreendimentos da Agricultura Familiar (COOPGEAF) no Sul da Bahia. 
pena investir na formalização dos empreendimentos ${ }^{45}$, uma vez que os grupos de mulheres são pequenos e nem sempre têm produção constante ao longo do ano, enquanto os custos de formalização são altos e permanentes. Essa questão é tão mais problemática quanto mais pobre é a região na qual os grupos estão inseridos. Alguns grupos conseguem acessar o PAA utilizando o CNPJ de organizações mistas, ou seja, mulheres pertencentes a grupos têm seus produtos incluídos em um projeto mais geral, mas mesmo assim nem sempre o nome das mulheres consta formalmente, pois depende do marido já estar ou não incluído. O PAA CDL Municipal, ao responsabilizar as prefeituras pelos contratos e pela prestação de contas, estabelece mecanismos que permitem prescindir de uma organização formal, mas por outro lado, ao privilegiar agricultores/as individualmente, não estimula a participação de grupos organizados.

Outro problema legal que dificulta a participação das mulheres é a adequação à legislação sanitária dos produtos processados ${ }^{46}$ e de origem animal $^{47}$, ambos importantes para as mulheres. As regras da vigilância sanitária em muitos casos são consideradas abusivas, por terem como parâmetros as grandes empresas. No caso do PAA, o fato da comercialização ser feita ao nível municipal é um facilitador, mas depende da prefeitura ter técnicos que autorizem a comercialização.

Mesmo assim, a pesquisa aponta que os grupos de mulheres que conseguiram ter acesso ao programa (com destaque para as modalidades de Compra Direta com Doação Simultânea) utilizaram-no como forma de alavancar a estruturação do grupo e da produção, aumentando e diversificando a produção, adequando-se progressivamente à legislação sanitária e permitindo o acesso a outros mercados, de forma mais autônoma, contribuindo para uma melhoria da renda e trazendo um conjunto de impactos positivos para a vida dessas mulheres. E a perspectiva de acesso ao PAA apareceu em alguns casos como um estímulo

\footnotetext{
${ }^{45}$ Essa postura apareceu, por exemplo, em lideranças de mulheres do Rio Grande do Sul, que consideram mais interessante para os grupos de mulheres investirem em mercados informais, como as feiras ou as vendas de casa em casa.

${ }^{46}$ No caso de polpas de frutas essa questão apareceu com maior importância.

${ }^{47}$ Em especial, ovos, galinha caipira, derivados de leite, carne de porco, mas também mariscos e pescados.
}

para a formalização de grupos de mulheres.

A existência de grupos de mulheres é um aspecto que indiscutivelmente "puxa para cima" os percentuais de participação de mulheres no PAA, pois há uma pressão por mais reconhecimento da participação das mulheres na vida produtiva, influenciando na maior presença de nomes de mulheres nos contratos. Os grupos organizados fazem com que, de fato, as mulheres tenham maior acesso ao programa e aos seus benefícios ${ }^{48}[56]$.

\section{CONCLUSÃO}

Os estudos de caso apontaram que embora seja bastante significativa a participação de mulheres agricultoras no Programa de Aquisição de Alimentos, essa participação ainda se dá muitas vezes de forma "anônima", uma vez que o percentual de mulheres formalmente registradas como fornecedoras em suas diferentes modalidades está bastante aquém do percentual de força de trabalho feminina empregada na produção fornecida.

O PAA, em suas distintas modalidades, indiscutivelmente valoriza o trabalho feminino, ao criar canais de comercialização para seus produtos, a um preço justo e com formas de operação que atendem às suas necessidades (entregas parceladas, constantes, em pequenas quantidades). No entanto, ainda existem fortes desafios para que possa contribuir de maneira efetiva para a construção de uma maior autonomia econômica das mulheres.

A forma como o Programa vem sendo implementado, assim como outras políticas voltadas para a agricultura familiar, tende a reforçar a ideia da unidade familiar de produção como um bloco homogêneo, desconsiderando as diferenças internas existentes. Permanecem, no interior das famílias agricultoras, desigualdades e subordinações, que não são consideradas.A presença das mulheres no mundo público ainda é uma exceção na agricultura familiar, apesar dos enormes avanços obtidos nos últimos anos em termos de direitos sociais e de políticas dirigidas a elas. Ainda estão presentes culturas organizacionais que operam com base em valores tradicionais patriarcais, que muitas vezes sequer são percebidos como tal.

\footnotetext{
${ }^{48}$ Essas questões podem ser melhor percebidas nos dados desagregados por município e por organizações proponentes. Para maiores detalhes, ver os relatórios originais da pesquisa.
} 
Práticas discriminatórias com relação às mulheres são encontradas com frequência, de forma naturalizada. A interpretação de que o titular do projeto "tem que ser" o homem, porque ele é o "chefe da família", "o cabeça da DAP", são exemplos desse comportamento, que se desdobra no preenchimento dos documentos em nome do homem, na possibilidade ou não de filiação de outros membros da família nos órgãos de representação com direito a voto, etc. Todos esses encaminhamentos reforçam a invisibilidade das mulheres como agentes econômicos e produtivos na agricultura familiar, contribuindo para que o seu espaço dentro da unidade de produção e da família continue como um espaço subordinado.

Essa situação tem sido modificada por pressão das próprias mulheres e também pelo grande esforço de parte dos agentes públicos em questionar a cultura dominante e propor ações que deem destaque ao protagonismo das mulheres no desenvolvimento local. Várias conquistas das mulheres no sentido da igualdade de gênero, além de reforçarem sua cidadania e terem impacto concreto na sua vida, vêm possibilitando que mulheres apareçam formalmente nos contratos do PAA, como o acesso à documentação pessoal, à titularidade da terra, à titularidade conjunta da DAP, a inclusão do seu nome nas notas fiscais de produtos agrícolas, a possibilidade de associação a sindicatos e cooperativas. As experiências produtivas e de comercialização feitas por grupos de mulheres, de processamento de produtos, de vendas nas feiras, ou ainda a sua presença nas discussões sobre o fornecimento para a alimentação escolar, também são exemplos dessa participação ativa e crescente das mulheres rurais em espaços importantes de afirmação da agricultura familiar como base para a promoção do desenvolvimento local.

De maneira geral, a baixa participação formal das mulheres no PAA e alguns subterfúgios utilizados pelas mesmas para viabilizar seu acesso direto ao programa, apontam que é necessário "superar" a identificação normalmente feita entre agricultura familiar $=$ família $=$ chefe da família $=$ marido. Indubitavelmente, entre os principais limitantes do ponto de vista jurídico e formal para uma remuneração mais justa da força de trabalho feminina no PAA está o fato de ser colocado um limite único de fornecimento por família (DAP), que desconsidera a existência de mão de obra diferenciada em seu interior. É necessário um reconhecimento, por parte do Estado, do valor do trabalho de cada um dos membros da unidade familiar de produção, para uma contribuição mais efetiva das políticas públicas na construção de relações mais igualitárias e democráticas no interior da família rural.

A dominação econômica e cultural à qual as mulheres estão submetidas na família se reflete na sua dificuldade de expressão na vida pública e perpetua um círculo vicioso de "não-direitos", de "não-cidadania" e de participação desigual no desenvolvimento. As mulheres em geral e as pobres em especial vivenciam, na sociedade, um sistemático processo cultural e político de expropriação das suas capacidades de agir publicamente e de exercício de seus direitos. $\mathrm{O}$ acesso a políticas públicas pode melhorar concretamente a vida das mulheres e permitir que haja uma valorização das suas contribuições para a sociedade, ajudando a superar valores e preconceitos ainda existentes, que impedem a sua plena realização como cidadãs.O desenho de políticas públicas precisa levar em conta essas questões se quiser fazer realmente políticas de cidadania como um passo importante da luta pela emancipação humana de homens e mulheres.

Este artigo é resultado de uma pesquisa nacional realizada pelas autoras durante 2009 e 2010, por solicitação da CONAB, como parte do Programa de Organização Produtiva das Mulheres Rurais. Uma versão preliminar foi apresentada no VIII Congresso Latino-americano de Sociologia Rural, em Porto de Galinhas, em 2010; e outra versão foi publicada em uma coletânea organizada por Andrea Butto e Isolda Dantas, "Autonomia e Cidadania: Políticas de organização produtiva para as mulheres no meio rural" (Brasília, Ministério do Desenvolvimento Agrário, 2011), sob o título "As mulheres agricultoras e sua participação no Programa de Aquisição de Alimentos (PAA)".

\section{REFERÊNCIAS}

1. Siliprandi E, Cintrão R. Pesquisa Participação das Mulheres no PAA - Quinto Produto - Análise quantitativa das modalidades operacionalizadas pelo MDS. S/1, Relatórios de Consultoria № 1-9, dez/2009 a nov/2010.

2. Paulillo MI. O peso do trabalho leve. Ciência Hoje. $1987 ; 5(28)$. 
3. Van Der Schaaf A. Jeito de mulher rural: a busca de direitos sociais e da igualdade de gênero no Rio Grande do Sul. Passo Fundo: UPF; 2001.

4. Santos G, Almeida MM. As relações de gênero na agricultura familiar. Diagnóstico do Pajeú/Pernambuco. Cadernos Diagnóstico, vol. 1. Recife: Casa da Mulher do Nordeste/Projeto Dom Helder Câmara; 2003.

5. Peixoto SL, Oliveira APG, Cruz EF. As relações de gênero no semi-árido: diagnóstico do território do sertão central cearense. Fortaleza: ESPLAR Centro de Pesquisa e Assessoria/Projeto Dom Helder Câmara; 2004.

6. Silva C, Ávila MB, Ferreira V. Nosso trabalho tem valor! Mulher e Agricultura Familiar. Recife: SOS Corpo Instituto Feminista para a Democracia/Movimento da Mulher Trabalhadora Rural do Nordeste; ago/2005.

7. Almeida MM. (Org.). As mulheres na agricultura de base familiar. Um trinômio real: produção agrícola, criação de animais e artesanato. Diagnóstico do potencial artesanal das mulheres agricultoras do Sertão do Pajeú - PE. Afogados de Ingazeira: Casa da Mulher do Nordeste; 2006.

8. Heredia B, Cintrão R. Gênero e acesso a políticas públicas no meio rural brasileiro. In: O progresso das mulheres no Brasil. Brasillia: UNIFEM/Fundação Ford/CEPIA; 2006. p. 102-31.

9. Sales CMV. Mulheres rurais: tecendo novas relações e reconhecendo direitos. Rev Estud Fem. 2007;15(2):437-43.

10. Nobre M, Siliprandi E, Quintela S, Menasche R. (Org.). Gênero e agricultura familiar. São Paulo: SOF Sempreviva Organização Feminista; 1998.

11. Oliveira CA. Quintais agroflorestais mulheres redesenham espaços de produção e reprodução no Maranhão. Agriculturas; experiências em Agroecologia (LEISA BRASIL). 2009;6(4):32-5.

12. Mourão PL. Diagnóstico das potencialidades das produções realizadas pelas mulheres rurais (relatório no 4). Consultoria prestada junto ao Ministério do Desenvolvimento Agrário. Projeto de Cooperação Técnica MDA/FAO - UTF/ BRA/057/BRA. Brasília; 2008.

13. Mourão PL. Relatório técnico contendo a sistematização das informações levantadas no mapeamento dos grupos produtivos de mulheres rurais (5/6). Projeto de Cooperação Técnica "Apoio às políticas e à participação social no desenvolvimento rural sustentável" - PCT IICA/MDA - NEAD; Brasília, 2008 (mimeo).

14. Gaiger LI. (Coord.). Sistematização de dados referentes à participação das mulheres nos empreendimentos econômicos e solidários cadastrados no Sistema Nacional de Economia Solidária (SIES). Universidade do Vale do Rio Sinos (Unisinos). Grupo de Pesquisa em Economia Solidária. São Leopoldo, Unisinos; 2008.

15. Silva NF. Relatórios da consultoria "Análise sobre a participação das mulheres e suas organizações na economia solidária no Brasil" (2 relatórios); Brasília, Projeto de Cooperação Técnica "Apoio às políticas e à participação social no desenvolvimento rural sustentável” - PCT IICA/MDA - NEAD, 2009a e 2009b (mimeo).

16. Duarte LMG, Brasil IC, Salviano OMMF. Agroindústria familiar e perspectivas de uma vida rural sustentável: um breve olhar sobre a experiência do PROVE - Distrito Federal/Brasil. In: Duarte LMG, Theodoro S. (Org.). Dilemas do cerrado. Entre o ecologicamente (in) correto e o socialmente (in) justo. Rio de Janeiro: Garamond; 2002. p. 205-22.

17. Duarte LMG, Salviano OMMF. O programa de verticalização da pequena produção familiar - PROVE - como alternativa ao desenvolvimento rural sustentável e à cidadania da mulher no campo. In: Duarte LMG, Theodoro S. (Org.). Dilemas do cerrado. Entre o ecologicamente (in) correto e o socialmente (in) justo. Rio de Janeiro: Garamond, 2002. p. 223-39.

18. Figueiredo LD. Empate nos babaçuais: do espaço doméstico ao espaço público - lutas das quebradeiras de coco babaçu no Maranhão. In: Woortmann E, Lopes A, Butto A, Molina C. (Org). Prêmio Margarida Alves. II Coletânea sobre estudos rurais e gênero. Brasília: MDA; 2007. p. 59-78.

19. Fernandes FC. A situação dos direitos humanos das mulheres fumicultoras no Estado do Rio Grande do Sul. In: Kassab, Marina (coord.) Kassab M. (Coord.). Tabaco e gênero no Brasil. Aliança Contra o Tabagismo acesso em 30 jun 2010. . Disponível em: http://actbr.org.br/ uploads/conteudo/438 tabaco e genero no brasil.pdf

20. Gomes D, Amaral W. Empreendimentos de Mulheres Rurais da Amazônia: "Articulação e caracterização das iniciativas". 
Belém: GTNA/Pão para o Mundo (PPM); 2005.

21.Relatórios CONAB (sumários executivos anuais sobre o PAA): 2003, 2004, 2005, 2006 e 2007 acesso em 08 nov 2011. . Disponível em: http://www.conab.gov.br

22.Sparovek G, Maule FE, Klug FSF, Klug ILF, Plata LAE, Goldszmidt R et al. Estudo comparado sobre a efetividade das diferentes modalidades do Programa de Aquisição de Alimentos - PAA - NE. FAO/MDS - UTF/BRA/064/ BRA. Piracicaba; 2006.

23. Botelho Filho FB, Carvalho AD. (Coord.). Estudo do impacto do PAA sobre os arranjos econômicos locais nas regiões Nordeste e Sul do Brasil. In: Vaitsman RPJ. (Org.). Cadernos de Estudos Desenvolvimento Social em Debate. no 5. 2007. Brasília, DF: Ministério do Desenvolvimento Social e Combate à Fome, Secretaria de Avaliação e Gestão da Informação, 2005.132 p.

24. Cordeiro A. Resultados do Programa de Aquisição de Alimentos - PAA: A perspectiva dos beneficiários. Relatório de consultoria Projeto PNUD/CONAB BRA/03/034. Brasília, julho de 2007.

25. Mattei L. Políticas públicas de combate à fome: o caso do programa de aquisição de alimentos da agricultura familiar no Estado de Santa Catarina. Sociedade e Desenvolvimento Rural. 2007;1(1):1-31.

26. Muller AL. A construção das políticas públicas para a agricultura familiar no Brasil: o caso do PAA. (Dissertação) Mestrado em Desenvolvimento Rural. Universidade Federal do Rio Grande do Sul, Faculdade de Ciências Econômicas, Programa de Pós-graduação em Desenvolvimento Rural. Porto Alegre; 2007.

27. Muller AL, Fialho MAV, Schneider S. A inovação institucional e a atuação dos atores locais na implementação do Programa de Aquisição de Alimentos no Rio Grande do Sul. In: Botelho FBF. Avaliação de Políticas de Aquisição de Alimentos. Brasília: Universidade de Brasília, CEAM, NEAGRI. 2007;7(27).

28. Vieira DFA, Viana CASO. Programa de Aquisição de Alimentos - PAA e sua relação com o modo de funcionamento da Agricultura Familiar. In: VII CONGRESSO BRASILEIRO DE SISTEMAS DE PRODUÇÃO, 2007, Fortaleza. Anais... Fortaleza: SBSP, 2007 [acesso em 09 nov 2011]. Disponível em: http:// www.conab.gov.br/OlalaCMS/uploads/arquivos/98d489 $\underline{\text { 686768a24d24fa7f0d1acabf81.pdf }}$

29. Vogt SPC, Souza RS. Políticas públicas e segurança alimentar: estudo de caso do Programa de Compra Antecipada Especial com Doação Simultânea (Fome Zero) no município de Tenente Portela-RS. In: VII Congresso Brasileiro de Sistemas de Produção, 2007, Fortaleza. Anais... Fortaleza, SBSP. 2007 [acesso em 09 nov 2011]. Disponível em: http://www.cnpat.embrapa. br/sbsp/anais/Trab Format PDF/112.pdf

30. Zimmermann AS, Ferreira APL. El Programa de Adquisición de Alimentos de la Agricultura Familiar en Mirandiba-Pe. In: Scotto G. (Org.). Aun hay tiempo para el sol. Probrezas rurales y programas sociales. Brasil, Venezuela, Guatemala: una mirada desde lo local. Rio de Janeiro: ActionAid, 2008. p. 28-64.

31. Pandolfo MC. O programa de aquisição de alimentos como instrumento revitalizador dos mercados regionais. Agriculturas. 2008;5(2):14-17.

32. Surita R. (Coord.). Alimentando a Cidadania: a força da sociedade civil junto a políticas públicas; relato sobre a Rede de Cooperação e Comercialização Solidária. Pelotas: Centro de Apoio ao Pequeno Agricultor; 2008.

33. JALIL, L. Relatórios de Campo da Pesquisa ActionAid sobre o PAA em Mrandiba (PE) e Esperantina (PI). [mensagem pessoal]. Mensagem recebida por emma. siliprandi@gmail.com em 14 out. 2009.

34. Grisa C. Desenvolvimento local, políticas públicas e meios de vida: uma análise do Programa de Aquisição de Alimentos (PAA). In: 47 $7^{\circ}$ CONGRESSO DA SOCIEDADE BRASILEIRA DE ECONOMIA, ADMINISTRAÇÃO E SOCIOLOGIA RURAL, 2009, Porto Alegre. Anais... Porto Alegre: SOBER, 2009 [acesso em 09 nov 2011]. Disponível em: http://www.sober.org. br/palestra/13/105.pdf

35. Martins SP. Análise dos dados de execução das modalidades Formação de Estoques e Compra Direta da Agricultura Familiar na Região Nordeste no período 20032008. Consultoria MDA/GTZ. Brasília; 2009.

36. Almeida LMMC, Botta Ferrante VLS. Programas de segurança alimentar e agricultores familiares: a formação de rede de forte coesão social a partir do Programa de Aquisição de Alimentos (PAA) no município de Araraquara - SP. In: $47^{\circ}$ CONGRESSO DA SOCIEDADE 
BRASILEIRA DE ECONOMIA, ADMINISTRAÇÃO E SOCIOLOGIA RURAL, 2009, Porto Alegre. Anais... Porto Alegre: SOBER, 2009. p. 1-21.

37. Becker C, Anjos FS, Caldas NV. Políticas públicas estruturantes e segurança alimentar: o caso do PAA. In: $47^{\circ}$ CONGRESSO DA SOCIEDADE BRASILEIRA DE ECONOMIA, ADMINISTRAÇÃO E SOCIOLOGIA RURAL, 2009, Porto Alegre. Anais... Porto Alegre: SOBER, 2009 [acesso em 09 nov 2011]. Disponível em: http://www.sober.org.br/palestra/13/88.pdf

38. Becker C. Mercados institucionais e agricultura familiar: análise do Programa de Aquisição de Alimentos (PAA) em municípios do Território Zona Sul do Rio Grande do Sul [dissertação]. Pelotas: Universidade Federal de Pelotas; 2010. 128 p.

39. Chmielewska D, Souza D, Lourete AA. O Programa de Aquisição de Alimentos da Agricultura Familiar (PAA) e as práticas orientadas ao mercado destes agricultores: Estudo de caso no Estado de Sergipe. Relatório de Pesquisa PNUD. Brasilia (mimeo), mar/2010.

40. Heredia B. A morada da vida - trabalho familiar de pequenos produtores no nordeste do Brasil. Rio de Janeiro: Paz e Terra; 1979.

41. Garcia JR, Afrânio R. O Sul: Caminho do roçado estratégias de reprodução camponesa e transformação social. São Paulo: Marco Zero, Brasília: Editora Univ. Brasilia, MCT/CNPq; 1989.

42. Departamento de Estudos Sócio-Econômicos Rurais/ CEMTR-PR. Gênero e Agricultura Familiar; cotidiano de vida e trabalho na produção de leite. Curitiba: DESER/ CEMTR-PR; 1996.

43. Ellis F. Household strategies and rural livelihood diversification. J Dev Stud. 1998;35(1):1-38.

44. Carneiro ML. Camponeses, agricultores e pluriatividade. Rio de Janeiro: Contra Capa Livraria; 1998.

45. De Grandi AB. Relações de trabalho nas familias agricultoras associadas a mini-usinas de leite no estado de Santa Catarina [dissertação]. Florianópolis: UFSC; 1999.93 p.

46. Ellis F. Rural livelihoods and diversity in developing countries. Oxford (UK): Oxford University Press; 2000.
47. Menasche R, Escher S. Gênero e agricultura familiar: cotidiano de vida e trabalho na produção de leite. DESER e Comissão Estadual de Mulheres Trabalhadoras Rurais do Paraná: Curitiba; 1996.

48. Dantas C, Monteiro J. Mulheres e semi-árido: Diagnóstico de gênero do território de Apodi. Centro Feminista 8 de Março/Projeto Helder Câmara: Mossoró, 2003. 38p. (Cadernos, 8 de Março, no 6).

49. Maia CJ. Trabalho, família e gênero: estratégias de reprodução social camponesa no Médio Jequitinhonha. In: Mulher e Trabalho, v. 4, n. 1, p. 89-103. FEE: Porto Alegre, 2004.

50. Magalhães RS. A "masculinização" da produção de leite. Revista de Economia e Sociologia Rural. Rev Econ Sociol Rural. 2009;47(1):275-300.

51. Brumer A. Previdência Social Rural e gênero. Sociologias. 2002;s/v(7):50-81.

52. Rego WL. Aspectos teóricos das políticas de cidadania: uma aproximação ao bolsa familia. Lua Nova. 2008;73:147-85.

53. Pereira LL, Santos LMP, Soares MD, Henrique FMCS, Guadagnin SC, Santos SMC. Efeitos do Programa Bolsa Família nas condições de vida de beneficiários em municípios de muito baixo IDH [acesso em 20 jun 2009]. Disponível em: http://www.undp-povertycentre.org/ publications/mds/33M.pdf

54. Ministério do Desenvolvimento Agrário/Secretaria da Agricultura Familiar. Declaração de Aptidão ao Agricultor Familiar ao PRONAF - Manual do Cadastrador.

55. Costa R. Comercialização e transformação da agricultura familiar: alguns pontos a discutir. In: Küster A, Mar JF. (Org.). Agricultura Familiar, Agroecologia e Mercado no Norte e Nordeste do Brasil. 2a ed. Fortaleza: KonradAdenauer-Stiftung; 2004. p. 67-74.

56. Culti MN. Mulheres na economia solidária: desafios sociais e políticos. IV Congreso Europeo CEISAL de Latinoamericanistas. Bratislava, 4 a 7/07/2004. 